() А.В. Витебская*, А.В. Попович, Е.Ю. Афонина, Ю.О. Костина, К.В. Алексанян, М.И. Грамматопуло, Е.А. Яблокова, О.В. Шпитонкова

Первый Московский государственный медицинский университет имени И.М. Сеченова, Москва

ОБОСНОВАНИЕ. При сочетании сахарного диабета 1 типа (СД1) с тяжелыми аутоиммунными и воспалительными заболеваниями ряду пациентов требуется одновременное назначение инсулина и глюкокортикоидов (ГК). Терапия ГК у пациентов с СД1 может ухудшать гликемический контроль.

ЦЕЛЬ. Выявить особенности инсулинотерапии при СД1 у детей и подростков, получающих ГК.

ОПИСАНИЕ КЛИНИЧЕСКИХ СЛУЧАЕВ. МЫ Наблюдали 5 пациентов с СД1, получавших ГК по поводу Ювенильного идиопатического артрита (ЮИА), ювенильной системной склеродермии (ЮССД), ювенильного дерматомиозита (ЮДМ), язвенного колита (ЯК) и реактивного артрита (РА).

Внутрисуставное введение ГК не оказывало значительного влияния на гликемический контроль.

При проведении пульс-терапии ГК гипергликемия и повышенная потребность в инсулине отмечались спустя 3-6 ч после приема ГК, сохранялись от нескольких часов до 3 суток после каждого введения.

При пероральной терапии ГК в высоких дозах наихудший контроль гликемии отмечался в дневное время. Для преодоления инсулинорезистентности использовались изменение времени введения и увеличение на 10\% дозы аналога инсулина пролонгированного действия, дополнительные инъекции аналогов инсулина ультракороткого действия, временное назначение человеческого инсулина короткого действия.

На фоне терапии ГК суточная доза инсулина была индивидуальна и могла достигать 2,0 Ед/кг. После перевода на поддерживающие дозы ГК или при прекращении терапии ГК пациенты возвращались К стандартной или относительно низкой потребности в инсулине.

Показатели гликированного гемоглобина $\left(\mathrm{HbA}_{1 c}\right)$ значительно различались между пациентами на разных этапах лечения, были максимальными при продолжительной терапии высокими дозами пероральных ГК, но в большей степени зависели от приверженности лечению пациента.

ЗАКЛЮчЕНИЕ. Улучшения гликемического контроля при приеме ГК удается добиться при своевременной коррекции доз инсулинотерапии, подборе индивидуальных схем, учитывающих время приема и особенности фармакокинетики ГК. Важную роль в гликемическом контроле играет приверженность пациента и его семьи к лечению СД1.

КЛЮЧЕВЫЕ СЛОВА: сахарный диабет 1 типа; дети; глюкокортикоиды

\title{
CHARACTERISTICS OF INSULIN THERAPY OF DIABETES MELLITUS TYPE 1 IN CHILDREN AND ADOLESCENTS RECEIVING GLUCOCORTICOIDS
}

(c) Alisa V. Vitebskaya*, Anastasia V. Popovich, Elena Y. Afonina, Yulia O. Kostina, Karina V. Aleksanyan, Maria I. Grammatopulo, Ekaterina A.Yablokova, Olga V.Shpitonkova

I.M. Sechenov First Moscow State Medical University, Moscow, Russia

BACKGROUND: In coexistence of diabetes mellitus type 1 (DM1) with severe autoimmune and inflammatory diseases some patients need simultaneous administration of insulin and glucocorticoids (GC). GC therapy in patients with DM1 can worsen glycemic control.

AIM: To determine characteristics of insulin therapy of DM1 in children and adolescents receiving GC.

DESCRIPTION OF CLINICAL CASES: We observed 5 patients with DM1 receiving GC for juvenile idiopathic arthritis (JIA), juvenile systemic sclerosis (JSS), juvenile dermatomyositis (JDM), ulcerative colitis (UC), and reactive arthritis (RA). Intra-articular administration of GC did not significantly influence glycemic control.

In case of GC pulse therapy hyperglycemia and increased insulin requirements were recognized in 3-6 hours after GC receipt, persisted from few hours up to 3 days after each administration.

While therapy with oral GC in high doses the worst glycemic control was registered in daylight hours. To overcome insulin resistance change of time of injection and 10\%-increase of long-acting insulin analogue, additional injections of ultrashort-acting insulin analogues, temporal prescription of short-acting human insulin were used. 
While GC therapy insulin daily dose was individual and could reach $2.0 \mathrm{U} / \mathrm{kg}$. After transition to maintaining doses of GC or discontinuation of GC therapy patients returned to standard or relatively low insulin requirements.

Levels of glycosylated hemoglobin differed significantly among patients at different stages of treatment, were maximal while long-term therapy with high doses of oral GC, but mostly depended on patient's compliance.

CONCLUSION: Bettering of glycemic control while receiving GC can be reached by timely dose correction of insulin therapy, selection of individual schemes, taking into account time of receipt and pharmacokinetic characteristics of GC. Adherence of the patient and his family to treatment of DM1 plays an important role in glycemic control.

KEYWORDS: diabetes mellitus; children; glucocorticoids

В последние десятилетия отмечается значительный рост эпидемиологических показателей заболеваний аутоиммунной природы - сахарного диабета 1 типа (СД1), системных заболеваний соединительной ткани и др. [1-3]. Сочетание двух и более аутоиммунных заболеваний у одного пациента также не является казуистичным. Необходимость одновременного лечения сразу нескольких патологических состояний осложняет подбор терапии. При сочетании СД1 с тяжелыми аутоиммунными и воспалительными заболеваниями пациенту может требоваться одновременное назначение инсулина и глюкокортикоидов (ГК). Терапия ГК у пациентов с СД1 считается нежелательной, так как может ухудшать гликемический контроль [4]. Однако в ряде случаев одномоментное назначение инсулина и ГК неизбежно.

\section{ЦЕЛЬ}

Выявить особенности инсулинотерапии при СД1 у детей и подростков, получающих ГК.

\section{ОПИСАНИЕ КЛИНИЧЕСКИХ СЛУЧАЕВ}

В Университетской детской клинической больнице (УДКБ) в течение 5 лет, с марта 2013 по март 2018 гг., наблюдались 5 пациентов с СД1, получавших ГК по поводу ювенильного идиопатического (ревматоидного) артрита (ЮИА), Ювенильной системной склеродермии (ЮССД), ювенильного дерматомиозита (ЮДМ), язвенного колита (ЯК) и реактивного артрита (РА). У 3 из них СД1 развился за 3, 4 и 7 лет соответственно до дебюта РА, ЮИА и ЮССД. У пациентов с ЮДМ и ЯК первое назначение ГК предшествовало выявлению СД1.

\section{Пациентка С., 12 лет, с ювенильным}

идиопатическим артритом.

Пациентка С. больна СД1 с 10 месяцев. Манифестация с классических симптомов. Сначала находилась на интенсифицированной терапии человеческими инсулинами Актрапид и Протафан, на этом фоне отмечалось лабильное течение со склонностью к гипогликемиям. Через год после начала заболевания переведена на аналоги инсулина аспарт и детемир, а еще через 2,5 года на гларгин. Потребность в инсулине до присоединения ЮИА соответствовала возрасту и длительности заболевания (0,7 Ед/кг/сут), а уровень гликированного гемоглобина $\left(\mathrm{HbA}_{1 c}\right)$ на этом этапе был близок к целевым значениям - до 7,8\%.

В 5 лет появились жалобы на припухлость левого коленного сустава, получала нестероидные противовоспалительные препараты (НПВП) с кратковременным эф- фектом. В первый год после присоединения заболевания суставов отмечены наихудшие значения $\mathrm{HbA}_{1 c}$ - от 9,2 до $11,1 \%$.

При обследовании в 6 лет выявлены высокие показатели антинуклеарного фактора, иммуноглобулина G, экссудативно-пролиферативные изменения в обоих коленных суставах, ограничение подвижности в III межфаланговом суставе правой кисти за счет болевого синдрома, ограничение разведения тазобедренных суставов; был диагностирован ЮИА. К терапии НПВП добавлен сульфасалазин 750 мг в сутки (38 мг/кг/сут). При проведении внутрисуставной пункции получено 36 мл из левого и 55 мл из правого коленного сустава; эффект от пункции кратковременный, отмечено нарастание припухлости суставов на следующий день после пункции. От внутрисуставного введения ГК в этот момент было решено воздержаться в связи с наличием СД1. Однако через месяц отмечено очередное обострение.

В это время пациентка получала инсулинотерапию В интенсифицированном режиме: аналог инсулина ультракороткого действия аспарт перед каждым приемом пищи и аналог инсулина пролонгированного действия гларгин (суммарная суточная доза инсулина 15,5 Ед $\left(0,7\right.$ Ед/кг)). До обострения ЮИА уровень $\mathrm{HbA}_{1 с}$ был близок к целевым значениям - 7,8\%. По данным дневника самоконтроля, в период обострения ЮИА отмечено ухудшение гликемического контроля - колебания гликемии с ежедневными пиками до 15-18 ммоль/л, которые купировались введением дополнительных доз аналога инсулина ультракороткого действия.

В связи с ухудшением состояния на фоне вирусной инфекции было принято решение о проведении курса терапии препаратами иммуноглобулина (Интратект 15 г (0,75 г/кг/курс)) с однократным пульсовым введением метилпреднизолона в дозе 125 мг. На этом фоне в течение первых суток, несмотря на коррекцию инсулинотерапии, отмечена гипергликемия до 21,4 ммоль/л (через 6 ч после внутривенного введения), затем - постепенная стабилизация гликемии через сутки после введения и уменьшение потребности в инсулине к 3-м суткам. Суточная доза инсулина в первые сутки достигала 1,8 Ед/ кг. При контроле $\mathrm{HbA}_{1 с}$ через полгода (без повторных введений ГК) - 8,5\%.

В 7-летнем возрасте на фоне обострения суставного синдрома однократно проводилась пункция коленных суставов с внутрисуставным введением метилпреднизолона. На фоне декомпенсации углеводного обмена, обусловленной воспалительным процессом, существенного изменения гликемии и увеличения потребности в инсулине на фоне внутрисуставного введения ГК отмечено не было. 
В возрасте 8 лет при очередном обострении ЮИА проведено повторное пульсовое введение метилпреднизолона (2 дня подряд по 125 мг) одновременно с инфузионной терапией препаратом иммуноглобулина (Пентаглобин 200 мл). Увеличение потребности в инсулине отмечалось в течение первых 2 сут после введения ГК. Суточная доза инсулина увеличивалась максимально до 2,0 Ед/кг, однако через 2 дня после последнего введения ГК гликемия и суточная потребность в инсулине возвратились к исходным значениям. Уровень $\mathrm{HbA}_{1 с}$ оставался прежним - 8,1\%.

Таким образом, за весь период наблюдения пациентке дважды проводились курсы пульс-терапии и однократно - внутрисуставное введение ГК. При обследовании через год (9 лет), несмотря на отсутствие клинического обострения ЮИА, сохранялась неудовлетворительная компенсация углеводного обмена $\mathrm{HbA}_{1 c}-9,1 \%$. Была предпринята попытка перевода на помповую инсулинотерапию (суточная потребность в инсулине составляла 0,7-0,9 Ед/кг/сут), однако спустя 5 мес пациентка вернулась к использованию шприц-ручек, объясняя свой выбор неудобством ношения внешнего устройства.

При дальнейшем наблюдении до 12-летнего возраста в связи с отсутствием тяжелых обострений ЮИА потребности в повторном назначении препаратов ГК не было. Отмечено ухудшение компенсации углеводного обмена - уровень $\mathrm{HbA}_{1 с}$ колебался от 7,9 до 9,1\%, что в большей степени обусловлено ухудшением самоконтроля и снижением комплаентности пациентки в подростковом возрасте.

Пациентка И., 13 лет, с ювенильной склеродермией.

Пациентка И. на момент первого назначения ГК была больна СД1 в течение 7 лет (с 6-летнего возраста). Манифестация СД1 с классическими симптомами. Сначала получала аналоги инсулина аспарт и детемир в интенсифицированном режиме. Через 5 лет от начала заболевания девочка переведена на помповую инсулинотерапию, однако через 1-2 мес после перевода отказалась от использования помпы. Тяжелых гипогликемий и эпизодов кетоацидоза никогда не фиксировалось, однако уровень $\mathrm{HbA}_{1 c}$ всегда был выше целевых значений: в первые 3 года заболевания - от 7,6\% до 8,5\%, далее - от 9,3\% до $11,7 \%$.

Через 6 лет от начала СД1 на внутренней поверхности левого бедра отмечено появление синего пятна, первоначально расцененного как гематома. Затем на левом бедре и голени появился очаг глубокой атрофии кожи и подкожно-жировой клетчатки, гиперпигментация кожи и фиброз в области левого коленного сустава и верхней трети голени, сгибательная контрактура левого коленного сустава.

Пациентка была госпитализирована в детское ревматологическое отделение приблизительно через год после появления первых симптомов ЮССД. Перед поступлением была проведена коррекция инсулинотерапии - на момент инициации терапии ГК пациентка получала аналоги инсулина аспарт и гларгин в интенсифицированном режиме в суточной дозе 0,9-1,0 Ед/кг/сут (гларгин 20 Ед, аспарт с учетом углеводного коэффициента (УК) 1 Ед/10 г углеводов (1 хлебная единица (1 XE)), коэффициента чувствительности (КЧ) 1 Ед/3 ммоль/л), $\mathrm{HbA}_{1 с}-9,2 \%$. На фоне пульс-терапии метилпреднизолоном в дозе 375 мг отмечено нарастание инсулинорезистентности, что потребовало увеличения доз инсулина как пролонгированного (22 Ед), так и ультракороткого действия (УК 2 Ед/1 ХЕ). На фоне проведения пульс-терапии гликемия в первые сутки достигала 19,6 ммоль/л (через 6 ч после введения препарата), после второго введения - 16,4 ммоль/л (через 2 ч после введения), после третьего введения - 16,1 ммоль/л (через 6 ч после введения). После второго внутривенного введения метилпреднизолона к терапии подключены таблетированные препараты - метилпреднизолон 16 мг в сутки и метотрексат в дозе 15 мг в неделю. Затем доза метилпреднизолона была постепенно уменьшена до 10 мг в сутки, пациентка продолжала принимать ГК в этой дозе в течение 6 месяцев, дозы инсулина были уменьшены до исходных (до назначения ГК), уровень самоконтроля пациентки остался на прежнем неудовлетворительном уровне, $\mathrm{HbA}_{1 c}-10,4 \%$.

Таким образом, описываемой пациентке препараты ГК назначались как в виде пульс-терапии, так и для длительного перорального приема. В течение следующего года после отмены терапии ГК девочка получала метотрексат, потребность в инсулине не изменилась. При контрольном обследовании через год, в период пребывания в стационаре, уровень гликемии колебался в пределах от 3,6 до 11,1 ммоль/л, несмотря на это, $\mathrm{HbA}_{1 с}$ оставался на прежнем уровне - 10,0\%.

Пациент К., 15 лет, с ювенильным дерматомиозитом.

Пациент К. впервые обратился с жалобами на эритему и отечность лица в 11 лет 10 месяцев, затем присоединились субфебрильная температура, выраженная мышечная слабость. При обследовании в 12 лет выявлено повышение показателей лактатдегидрогеназы, креатинфосфокиназы и скорости оседания эритроцитов, назначен преднизолон в дозе 45 мг (1 мг/кг). После начала приема преднизолона выявлена гипергликемия 12,9 ммоль/л с последующим нарастанием до 22,3 ммоль/л. На фоне однократного введения инсулина Актрапид гликемия нормализовалась. В связи с этим преднизолон был отменен, рекомендован прием хлорохина. Однако сохранялись выраженные симптомы ЮДМ. На фоне соблюдения ограничения приема легкоусвояемых углеводов проведено обследование по месту жительства, подтвердившее СД (глюкоза натощак 6,4 ммоль/л, через 2 ч после стандартной нагрузки глюкозой (75 г) - 12,7 ммоль/л, $\mathrm{HbA}_{1 с}-$ 8,2\%). При исследовании антител к глутаматдекарбоксилазе получено пограничное значение 10,65 Ед/мл (норма до 10), что не позволило однозначно говорить о наличии СД1.

При поступлении в УДКБ в связи с тяжестью состояния, обусловленной ЮДМ, было решено начать терапию ГК. Уровень НbА 1 в этот момент на фоне соблюдения низкоуглеводной диеты был пограничным - 6,2\%, при повторном исследовании антител, типичных для СД1, получены положительные антитела к бета-клеткам 2,3 Ед/мл (положительно >1,05, в норме - отрицательно), а позднее и к фосфотирозинфосфатазе - $80 \mathrm{ME} / \mathrm{Mл} \mathrm{(положительно}$ >10). Таким образом, диагноз СД1 был подтвержден.

После начала терапии ГК первые 3 сут на фоне приема 20 мг преднизолона (10 мг в 7.00 и 10 мг в 13.00) гликемия сохранялась от 4,8 ммоль/л в утреннее время 
Таблица 1. Терапия и показатели гликемии пациента К. с ювенильным дерматомиозитом в течение 3 лет наблюдения

\begin{tabular}{lccc}
\hline \multicolumn{1}{c}{ Время с начала лечения } & Преднизолон, мг & HbА, $_{\mathbf{1 c}}$. & Инсулин \\
\hline Начало лечения & 45 & 6,2 & Гларгин 10 Ед, Актрапид 18 Ед \\
Через 3 месяца & 32,5 & 8,1 & Гларгин 11 Ед, Актрапид 21 Ед \\
Через 6 месяцев & 17,5 & 6,3 & Гларгин 6 Ед, Актрапид 20 Ед \\
Через 1 год & 10 & 6,2 & Инсулиновая помпа, аспарт 0,5-0,6 Ед/кг \\
Через 2-3 года & 7,5 & $5,3-6,2$ & Инсулиновая помпа, аспарт 0,5-0,6 Ед/кг \\
\hline
\end{tabular}

Примечание: $\mathrm{HbA}_{1 с}$ - гликированный гемоглобин

до 11,7 ммоль/л в послеобеденное время. На 4-е сутки доза увеличена до 30 мг (по 15 мг в 7.00 и 13.00), начата инсулинотерапия аналогом инсулина длительного действия гларгин в дозе 3 Ед. В связи с традиционным для пациентов с ревматическими заболеваниями утренним приемом всей дозы преднизолона и особенностями фармакодинамики аналога инсулина пролонгированного действия было решено вводить гларгин в утренние часы. На этом фоне пик гипергликемии сохранялся с 13 до 21 ч - до 10,9 ммоль/л с последующей нормализацией гликемии к утру (5,3 ммоль/л). На 5-е сутки доза преднизолона увеличена до 40 мг в сутки (20 мг в 7.00, 15 мг в 13.00, 5 мг в 15.00), доза гларгина увеличена до 5 Ед. На этом фоне - пик гликемии до 18,9 ммоль/л в 18 ч с последующей нормализацией к утру (5,3 ммоль/л). В связи с повторными гипергликемиями было принято решение о назначении интенсифицированного режима введения инсулина. С учетом особенностей фармакодинамики принимаемых ГК (инсулинорезистентность длительностью несколько часов) было решено выбрать человеческий инсулин короткого действия вместо традиционно применяемых аналогов ультракороткого действия. Пациент был выписан из стационара на терапии преднизолоном (20 мг в 7.00, 15 мг в 13.00, 10 мг в 15.00) и инсулинотерапии (гларгин утром по 10-11 Ед, Актрапид за 30 минут до завтрака, обеда и ужина по 6,0, 8,0, 4,0 Ед соответственно, суточная доза 0,6 Ед/кг/сут).

При обследовании через 3 мес уровень $\mathrm{HbA}_{1 с}$ был близок к целевым значениям - 8,1\%. В этот момент доза преднизолона была снижена до 32,5 мг в сутки, дозы инсулина не претерпели существенных изменений (гларгин утром по 11 Ед, Актрапид за 30 минут до завтрака, обеда и ужина по 8,0, 9,0, 4,0 Ед соответственно, суточная доза 0,7 Ед/кг/сут).

Через 6 мес после начала терапии на фоне уменьшения дозы преднизолона до 17,5 мг отмечена стабилизация гликемии в целевом диапазоне $\left(\mathrm{HbA}_{1 c} 6,3 \%\right)$, уменьшена доза гларгина до 6 Ед (суточная доза инсулина 0,5 Ед/кг).

В течение следующего полугодия доза преднизолона была уменьшена до 10 мг в сутки, пациент был переведен по месту жительства на помповую инсулинотерапию. На этом фоне $\mathrm{HbA}_{1 c}-6,2 \%$, потребность в инсулине 0,5-0,6 Ед/кг/сут. В течение следующих двух лет наблюдения доза преднизолона уменьшена до 7,5 мг, $\mathrm{HbA}_{1 с}$ сохранялся в пределах целевых значений 5,3-6,2\%, потребность в инсулине не увеличилась (0,5-0,6 Ед/кг) (табл. 1).
На протяжении всего периода наблюдения пациента на фоне приема пероральных препаратов ГК отмечается очень высокий уровень приверженности лечению как самого ребенка, так и его семьи, а также активное взаимодействие с медицинским персоналом.

Пациентка Н., 14 лет, с язвенным колитом.

Диагноз тотального ЯК установлен по месту жительства в возрасте 7 лет, подтвержден результатами колоноскопии и ступенчатой биопсии слизистой оболочки толстой кишки с последующим морфологическим исследованием. Несмотря на базисную противовоспалительную терапию препаратами месалазина в дозе до 3,0 г в сутки (40 мг/кг), наблюдались частые (2-3 раза в год) рецидивы основного заболевания, тотальная протяженность поражения. В возрасте 9-12 лет в связи с клинической ремиссией ЯК отменена базисная терапия месалазином. В 13 лет отмечено выраженное обострение ЯК. Вследствие недостаточной эффективности сочетанной орально-ректальной базисной терапии месалазином, к лечению колита был добавлен азатиоприн 75 мг в сутки (2 мг/кг), с последующей заменой его на 6-меркаптопурин и полной отменой иммуносупрессоров через 6 мес из-за непереносимости препаратов этой группы. В это же время был впервые назначен пероральный прием ГК - преднизолон в дозе 35 мг в сутки (1 мг/кг). Через 2 нед после начала терапии отмечено повышение гликемии натощак до 8,9 ммоль/л, в связи с чем пациентка была срочно госпитализирована. При поступлении в стационар по месту жительства отмечена гликемия 15,6 ммоль/л. В течение суток отмечено нарастание гликемии выше 33 ммоль/л (по данным глюкометра), кетонурия 0,5\%. В связи с гипергликемией по жизненным показаниям была начата инсулинотерапия. При дальнейшем обследовании было выявлено повышение уровня $\mathrm{HbA}_{1 c}(7,0 \%)$ и титров типичных для СД1 антител к бета-клеткам (1:4), глутаматдекарбоксилазе (1233 Ед/л) и фосфотирозинфосфатазе (32,6 MЕ/мл). На основании полученных результатов был подтвержден диагноз СД1.

В течение следующих 2 мес после дебюта СД1 в связи с тяжестью обострения ЯК пациентка получала преднизолон в дозе до 50 мг в сутки (1,5 мг/кг). На этом фоне сохранялась высокая, особенно для впервые выявленного диабета, потребность в инсулине - до 1,5 Ед/кг (до 15 Ед гларгина и до 40 Ед аспарта (по 9-13,5 Ед на прием пищи)). В это время у пациентки отмечался дефицит массы тела рост 154 см, масса тела 35 кг, индекс массы тела (ИМТ) 
Таблица 2. Терапия и показатели гликемии пациентки Н. с язвенным колитом на фоне пульс-терапии глюкокортикоидами, приведшей к возобновлению инсулинотерапии

\begin{tabular}{|c|c|c|c|}
\hline День & Пульс-терапия ГK* & Гликемия & Инсулин, доза, УК* \\
\hline До пульс-терапии ГК & - & 3,6-6,2 ммоль/л & - \\
\hline День 1 & Метилпреднизолон 250 мг & - & - \\
\hline День 2 & - & - & - \\
\hline День 3 & - & 5,2 ммоль/л & - \\
\hline День 4 & Метилпреднизолон 250 мг & - & - \\
\hline День 5 & - & 9,9-12,9 ммоль/л & Аспарт 1 Ед/XE* \\
\hline День 6 & Метилпреднизолон, 125 мг & 5,7-16,0 ммоль/л & Аспарт 1 Ед/XЕ \\
\hline День 7 & - & 8,0-20,2 ммоль/л & Гларгин 3 Ед, аспарт УК 1,5 Ед/ХЕ \\
\hline День 8 & - & 5,6-8,8 ммоль/л & Гларгин 2 Ед, аспарт УК 1,2 Ед/ХЕ \\
\hline День 9 & & 4,0-10,8 ммоль/л & Гларгин 2 Ед, аспарт УК 1,0 Ед/ХЕ \\
\hline День 10 & Метилпреднизолон, 125 мг & 5,6-18,0 ммоль/л & Гларгин 2 Ед, аспарт УК 1,5 Ед/ХЕ \\
\hline День 11 & & 4,6-12,9 ммоль/л & Гларгин 2 Ед, аспарт УК 1,2Ед/XЕ \\
\hline День 12 & & 4,9 ммоль/л & Гларгин 2 Ед, аспарт УК 1,0 Ед/ХЕ \\
\hline
\end{tabular}

Примечания: *ГК - глюкокортикоиды; УК - углеводный коэффициент; XE - хлебная единица (10 г углеводов)

14,56 кг/м², число стандартных отклонений от среднего для данного возраста и пола (standard deviation score (SDSИMT)) - 2,54. Несмотря на высокие дозы инсулина и тщательный самоконтроль, в дневное время, особенно в первую половину дня (период действия преднизолона), сохранялась гипергликемия с непредсказуемыми колебаниями от 9 до 20 ммоль/л. В дальнейшем, на протяжении 4 мес, на фоне улучшения клинической картины ЯК проводилось постепенное снижение доз преднизолона вплоть до полной отмены. Одновременно с уменьшением дозы ГК отмечена сначала нормализация гликемии, затем - снижение потребности в инсулине и тенденция к гипогликемиям, что привело к полной отмене инсулинотерапии.

На момент поступления в гастроэнтерологическое отделение УДКБ, через 3 мес после отмены инсулинотерапии, у пациентки отмечались нормальные показатели гликемии в течение суток - от 3,5 до 5,7 ммоль/л по данным глюкометра, что подтверждалось уровнем $\mathrm{HbA}_{1 c}-5,3 \%$. Также отмечена положительная динамика в увеличении массы тела пациентки по сравнению с периодом обострения ЯК (38 кг, SDS ИМТ - 1,84). При обследовании подтверждена низкая активность ЯК по PUCAI (Paediatric Ulcerative Colitis Activity Index, педиатрический индекс активности язвенного колита) - 35 баллов, эндоскопически - левосторонний эрозивный колит, морфологически в биоптатах слизистой оболочки толстой кишки подтвержден диагноз активного ЯК. Базисная терапия основного заболевания - месалазин 3,0 г в сутки (60 мг/кг).

После проведения колоноскопии клинически отмечено ухудшение ЯК - учащенный до 3-4 раз в сутки кашицеобразный стул с кровью. В связи с этим было решено провести пульс-терапию ГК. Гликемия по результатам лабораторного биохимического анализа крови до введения ГК была зафиксирована на уровне 6,2 ммоль/л.
При первом внутривенном введении 250 мг метилпреднизолона гликемия оставалась в пределах нормальных значений - через 2 сут натощак 5,2 ммоль/л (табл. 2).

Повторное введение 250 мг метилпреднизолона проведено через 3 сут. Первые несколько часов гликемия не измерялась, симптомы гипергликемии отсутствовали. На следующий день утром впервые после 3 мес клинико-лабораторной ремиссии СД1 выявлена гипергликемия натощак 9,9 ммоль/л, в связи с чем была возобновлена инсулинотерапия аналогом инсулина ультракороткого действия аспарт в дробном режиме на приемы пищи с УК 1 Ед/ХЕ. Гликемия в течение 1-х суток после возобновления инсулинотерапии (через сутки после введения метилпреднизолона) - от 8,8 до 12,9 ммоль/л. К следующему утру, без дополнительных инъекций инсулина, гликемия самопроизвольно снизилась до 5,7 ммоль/л (табл. 2).

Третье капельное введение метилпреднизолона проведено в уменьшенной дозе 125 мг через 2 сут после второго введения. В течение 1-х суток после инфузии на фоне продолжающейся дробной инсулинотерапии гликемия - от 8,9 до 20,8 ммоль/л, самопроизвольное снижение гликемии к следующему утру до 8,0 ммоль/л. В течение 2-х суток, несмотря на увеличение УК аспарта до 1,5 Ед/XЕ, сохранялась гипергликемия до 20,2 ммоль/л. В связи с этим пациентка была переведена на интенсифицированную схему инсулинотерапии - в 22 ч добавлена инъекция аналога инсулина продленного действия гларгин в дозе 3 Ед. На следующие (3-и после введения метилпреднизолона) сутки отмечена стабилизация гликемии от 5,6 до 8,8 ммоль/л, УК аспарта без изменений 1,5 Ед/XE, доза гларгина была уменьшена до 2 Ед. На 4-е и 5-е сутки гликемия была относительно стабильна от 4,0 до 10,8 и от 4,1 до 7,8 ммоль/л соответственно. Это позволило снизить УК аспарта сначала до 1,2, а затем до 1,0 Ед/ХЕ при прежней дозе гларгина 2 Ед (см. табл. 2). 
Вт 9 янв.

Глюкоза Inol/L

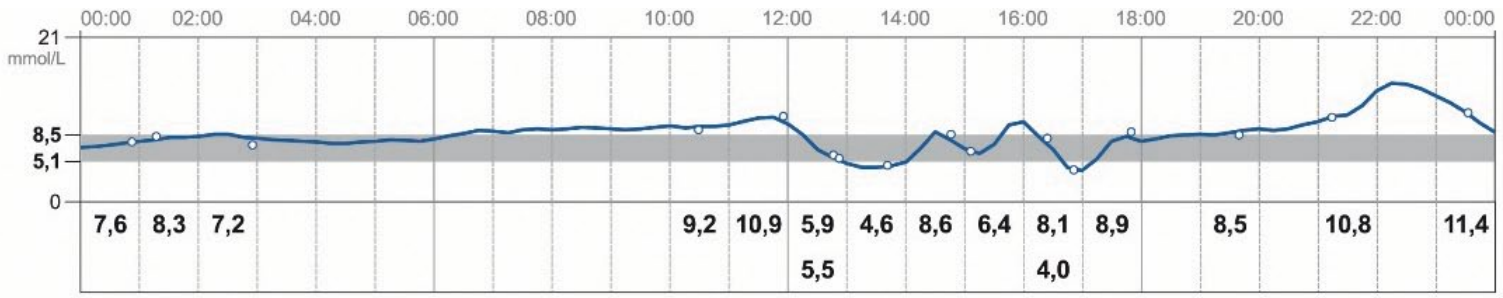

Ср 10 янв.

Глюкоза

mmо/L.

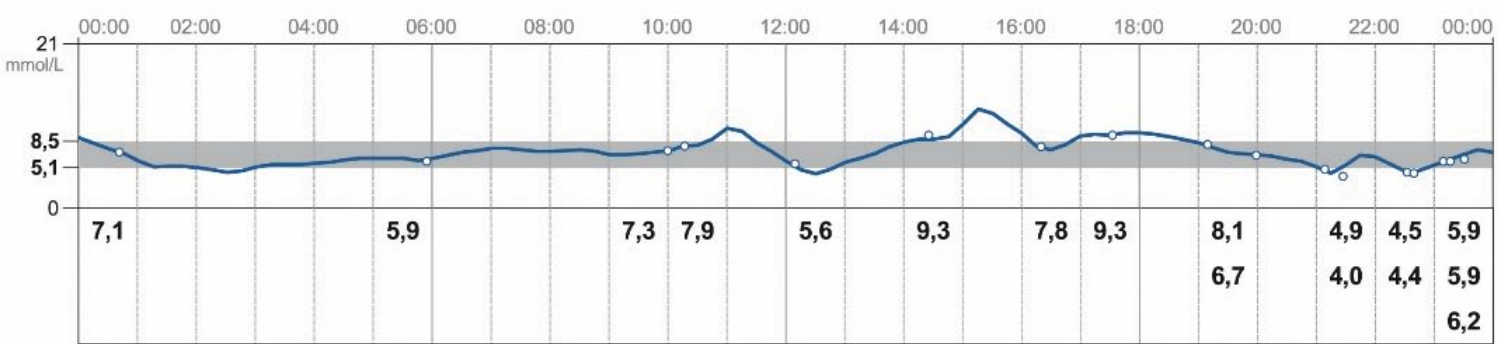

Чт 11 янв.

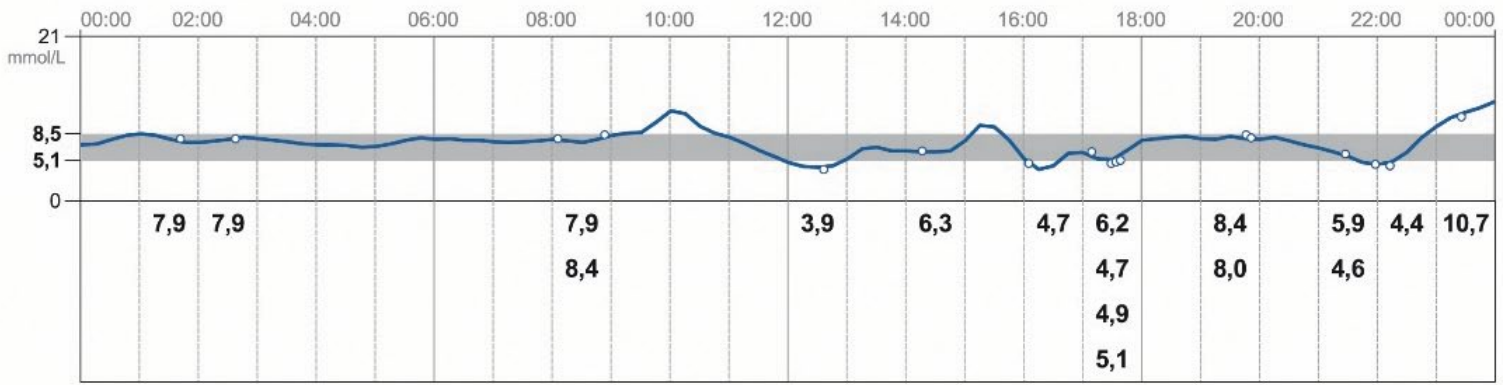

Пояснения. ○Сканирование датчика

Рис. 1. Показатели гликемии по данным флеш-мониторинга пациента К. до манифестации реактивного артрита.

На фоне четвертого введения метилпреднизолона в дозе 125 мг (через 5 сут после предыдущего) начата иммунобиологическая терапия инфликсимабом в дозе 200 мг (5,5 мг/кг). Гликемия в течение первых суток в пределах от 5,6 до 18,0 ммоль/л, УК аспарта вновь увеличен до 1,5 Ед/XЕ, введены дополнительные инъекции с учетом КЧ 1 Ед/ 3,0 ммоль/л, доза гларгина без изменений. В течение следующих 2 сут гликемия от 4,6 до 12,9 ммоль/л, УК аспарта уменьшен сначала до 1,2, а через сутки - до 1,0 Ед/ХЕ (см. табл. 2). На этих дозах инсулинотерапии пациентка выписана из стационара под наблюдение гастроэнтеролога и эндокринолога по месту жительства в состоянии клинической ремиссии ЯК (активность ЯК по PUCAI - 0 баллов).

Необходимо отметить очень высокий уровень комплаентности пациентки и ее матери как при пероральном приеме ГК, так и в период пульс-терапии, желание сотрудничать с медицинским персоналом для достижения целевых показателей гликемии, что позволило в достаточно короткие сроки добиться компенсации углеводного обмена.

Пациент К。, 12 лет, с реактивным артритом.

СД1 был диагностирован в 9-летнем возрасте, гликемия в дебюте заболевания - 20,0 ммоль/л. При госпитализации была начата инсулинотерапия аналогами инсулина глулизином и гларгином. В дальнейшем отмечено достаточно стабильное течение заболевания, со склонностью к гипогликемиям. Уровень $\mathrm{HbA}_{1 с}$ измерялся регулярно каждые 3 мес и в большинстве случаев был близок к целевым значениям либо соответствовал компенсации - от 5,8 до 8,0\%. Данные флеш-мониторинга гликемии, постоянно проводимого в течение года, предшествующего обращению в стационар, также свидетельствовали о компенсации (рис. 1).

В 12-летнем возрасте в связи с появлением боли и отечности правого коленного сустава пациент был впервые проконсультирован ортопедом. Назначенная терапия НПВП не имела эффекта, отечность нарастала, присоединилось нарушение походки. При обращении в детское ревматологическое отделение УдкБ в правом коленном суставе выявлены экссудативные изменения, сгибательная контрактура, резкое ограничение и болезненность движений, отмечалась пастозность правого голеностопного сустава, нарушение походки. По результатам проведенного обследования был диагностирован реактивный артрит.

С первых дней появления воспалительных изменений суставов у пациента отмечена декомпенсация углеводного обмена (рис. 2). По данным дневника самоконтроля, гликемия в течение дня колебалась от 3,0 до 17,0 ммоль. Это потребовало коррекции доз аналогов инсулина как пролонгированного (доза гларгина была увеличена с 9 до 12 Ед), так и ультракороткого действия (УК увеличен с 2 до 2,5 Ед/1 ХЕ), что привело к увеличению суточной дозы инсулина с 36 Ед (0,7 Ед/кг/сут) до 44 Ед (0,9 Ед/кг/сут).

Мальчику проведена пункция коленных суставов с последующим внутрисуставным введением метилпреднизолона в дозе 40 мг. Показатели гликемии до и после манипуляции были зафиксированы с использованием флеш-мониторинга (рис. 3). Гипергли- 
Чт 1 февр.

Глюкоза
mmo/l/L

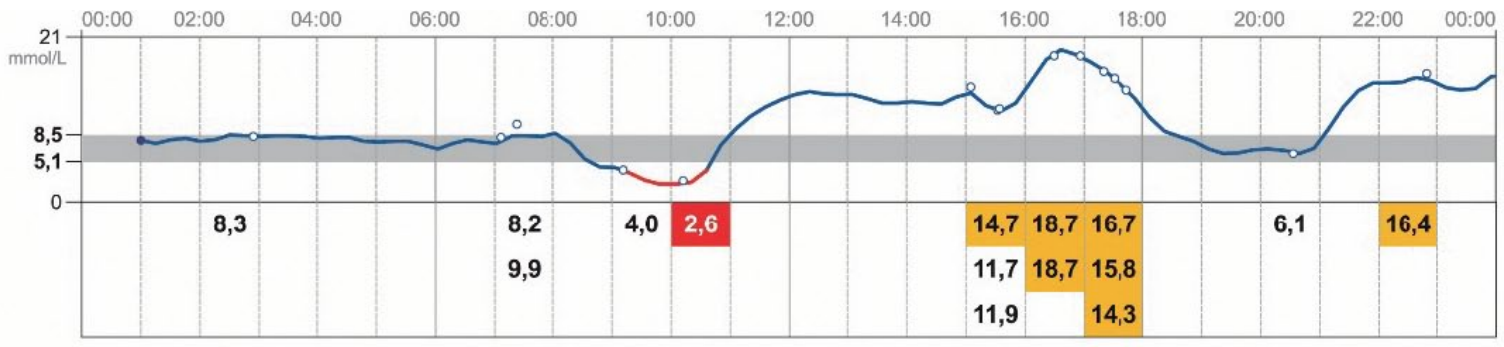

Пт 2 февр.

Глюкоза

$\mathrm{mmol} / \mathrm{L}$

Сб 3 февр.

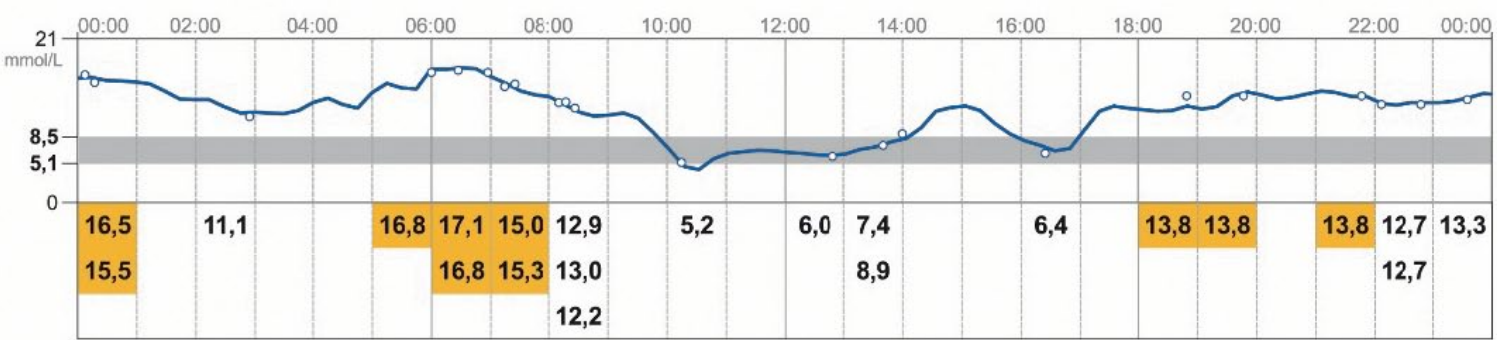

Глюкоза

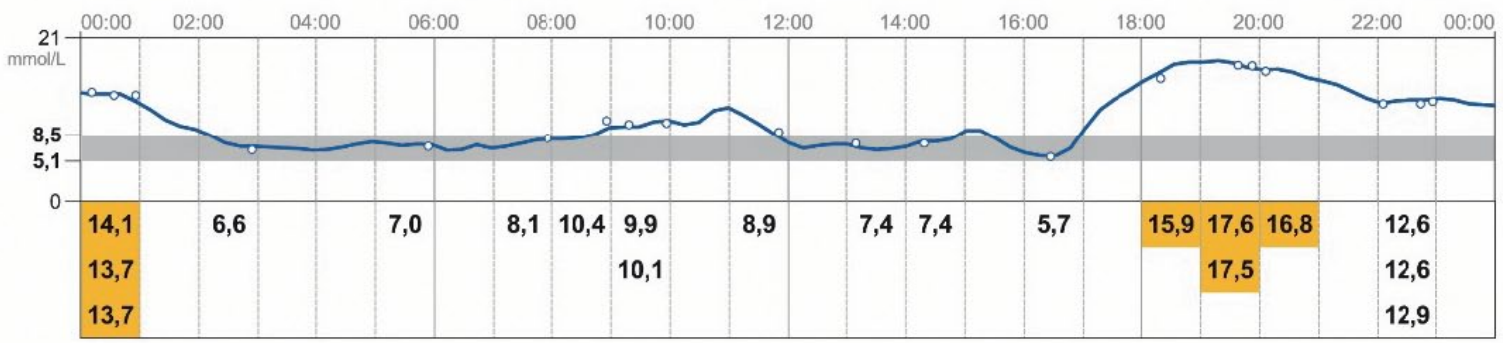

Пояснения. Высокий ур. глюкозы $(>13,3)$ Шизкий ур. глюкозы $(<3,9) \circ$ Сканирование датчика • Новый датчик

Рис. 2. Показатели гликемии по данным флеш-мониторинга пациента К. на фоне манифестации реактивного артрита.

Чт 22 февр.

Глюкоза

Глюкоге

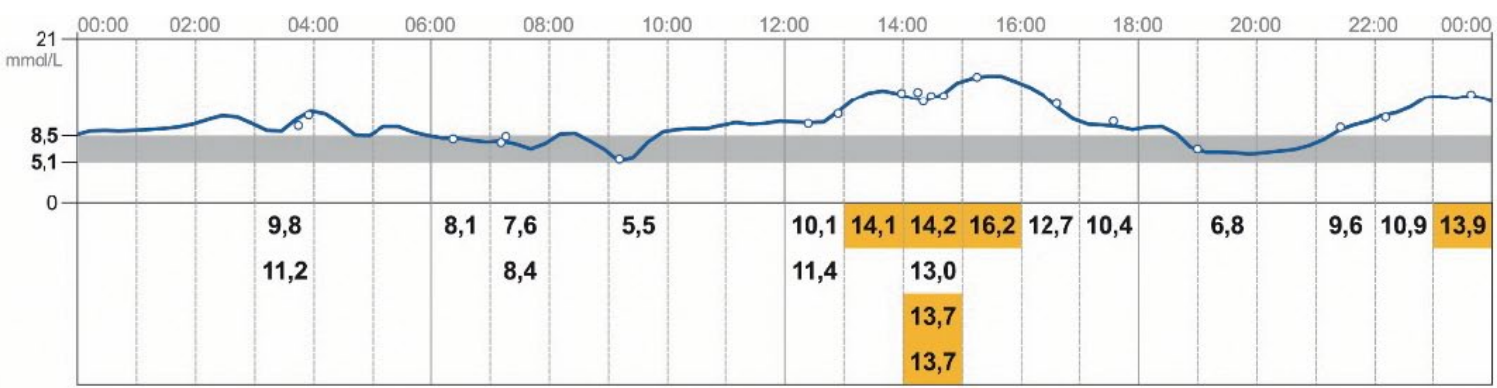

Пт 23 февр.



Пояснения. Высокий ур. глюкозы (>13,3) ○ Сканирование датчика

Рис.3. Показатели гликемии по данным флеш-мониторинга пациента К. на фоне внутрисуставного введения глюкокортикоидов (22 февраля в 12 часов 30 минут) и на следующий день (без введения глюкокортикоидов).

кемия в ответ на внутрисуставное введение ГК носила умеренный кратковременный характер и не требовала существенной коррекции инсулинотерапии. Интересно отметить, что на фоне уменьшения воспаления и нормализации функции правого коленного сустава отмечена стабилизация гликемии и снижение потребности в инсу- лине - уже через 10 дней суточная доза инсулина составила 40 Ед (0,8 Ед/кг/сут) (рис. 4).

За период наблюдения пациенту потребовалось однократное внутрисуставное введение ГК. При повторном обследовании через 6 мес клинических проявлений реактивного артрита не отмечено, $\mathrm{HbA}_{1 c}$, $8 \%$. 
Сб 3 марта

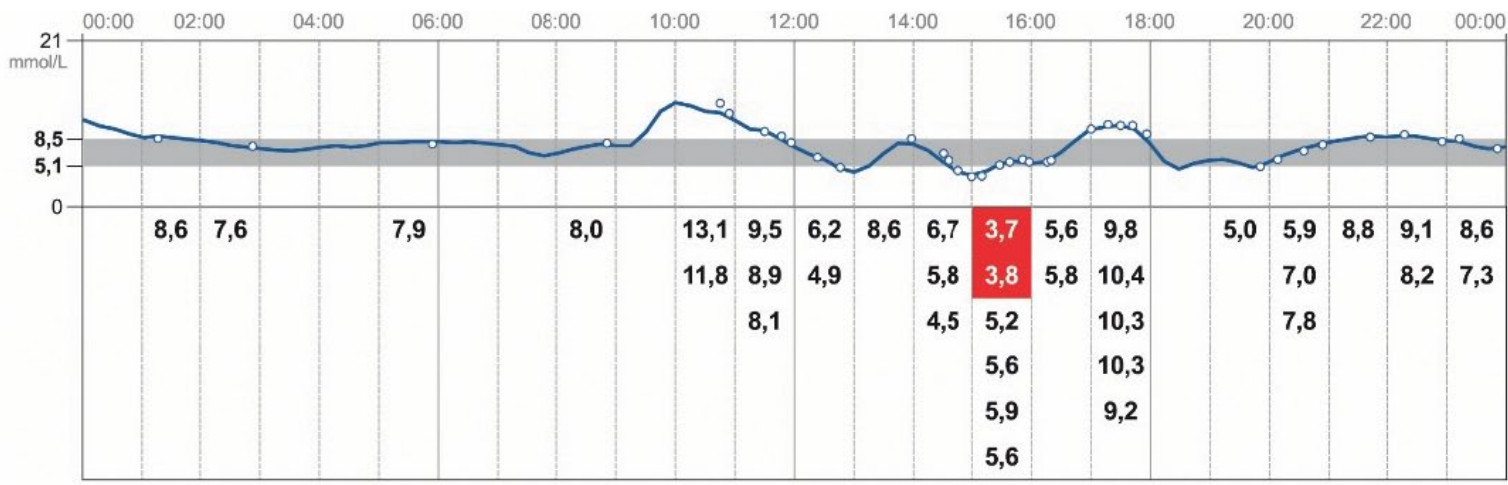

Вс 4 марта

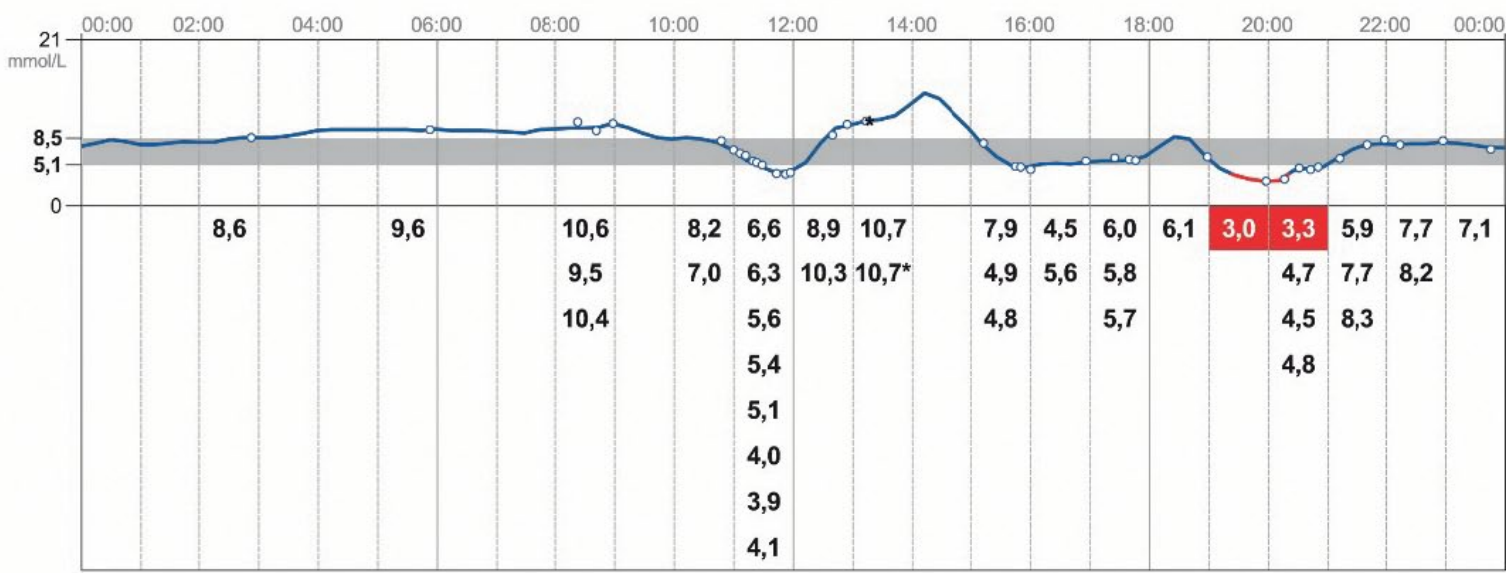

Пояснения. Низкий ур. глюкозы $(<3,9) *$ Полосочный тест ०Сканирование датчика

Рис. 4. Показатели гликемии по данным флеш-мониторинга пациента К. через несколько дней после внутрисуставного введения глюкокортикоидов

\section{ОБСУЖДЕНИЕ}

Во всех представленных клинических случаях пациенты детско-подросткового возраста одновременно с инсулинотерапией получали препараты ГК по поводу различных аутоиммунных и воспалительных заболеваний.

Ювенильный идиопатический (ревматоидный) apmpum - тяжелое деструктивно-воспалительное заболевание суставов у детей и подростков. Заболеваемость ЮИА составляет 2-16 на 100000 детского населения в возрасте до 16 лет, а распространенность варьирует от 11,7 до 35 на 100000 [3]. Сочетание ЮИА с СД1 хорошо изучено. Распространенность СД1 при наличии ЮИА значительно превышает аналогичные показатели в популяции без ЮИА и колеблется, по результатам различных исследований, от 0,19\% у детей [5] до 1,14\% у взрослых [6]. По данным Финского национального исследования, заболеваемость одновременно СД1 и ЮИА за 30 лет наблюдения увеличилась в 4,5 раза [7]. Согласно литературным данным, для детей с сочетанием ЮИА и СД1 характерны более низкий рост по сравнению с детьми с ЮИА, но без диабета, а также более низкие значения $\mathrm{HbA}_{1 c}$ по сравнению с детьми с СД1 без ЮИА, что, по мнению исследователей, обусловлено более тщательным контролем гликемии у этой группы пациентов [5].

В описываемом нами случае уровень $\mathrm{HbA}_{1 с}$ до заболевания ЮИА у пациентки был ближе к целевым значениям, чем на фоне рецидивирующего течения воспалительного заболевания. Мы предполагаем, что сам факт частых декомпенсаций ЮИА также вносит существенный вклад в ухудшение контроля гликемии.

Ювенильная системная склеродермия - хроническое аутоиммунное заболевание, с дебютом болезни до 16-летнего возраста, которое проявляется характерным фиброзно-склеротическим поражением кожи, опорно-двигательного аппарата, с возможным вовлечением в процесс внутренних органов, и синдромом Рейно. Это относительно редкое состояние, заболеваемость составляет примерно 0,05 на 100000 детского населения в год [3]. Распространенность системной склеродермии у взрослых колеблется в пределах 19-75 на 100000 населения, заболеваемость - 0,45-1,4 на 100000 населения в год, при этом доля детей в возрасте до 16 лет, больных ЮССД, составляет менее 3\% [3]. Кроме этого, для пациентов с ЮССД характерна относительно низкая, по сравнению со здоровой популяцией, распространенность СД1 [8]. Еще одной особенностью сочетания ЮССД и СД1 является то, что кожные изменения при СД1 часто воспринимаются как осложнения основного заболевания. Согласно литературным данным, в последние годы отмечается рост распространенности некоторых состояний, ассоциированных с СД1, в частности диабетической склеродактилии, которую нередко сложно бывает дифференцировать со склеродермией $[9,10]$. Одни авторы связывают эти состояния с наличием микрососудистых осложнений и выраженными колебаниями гликемии [9], - другие, наоборот, доказывают отсутствие подобной связи [10].

В нашем случае ЮССД, несмотря на выраженность клинических проявлений, в течение нескольких месяцев оставалась нераспознанной, и диагноз был установлен уже на стадии формирования контрактуры коленного сустава. Необходимо также отметить, что недостаточный уровень компенсации СД1 на протяжении всего заболевания обусловлен в первую очередь низкой комплаентностью пациентки, даже несмотря на высокую мотивацию уменьшить проявления и последствия ЮССД. 
Ювенильный дерматомиозит - тяжелое прогрессирующее системное заболевание с преимущественным поражением поперечнополосатой мускулатуры, кожи и сосудов микроциркуляторного русла, нередко осложняющееся кальцинозом и гнойной инфекцией. Это достаточно редкое заболевание, его распространенность составляет 4 на 100000 детского населения [11], заболеваемость - 2-4 на 1000000 детского населения в год, благодаря чему ЮДМ больны лишь 5\% детей с ревматическими заболеваниями. Сочетание СД1 с ЮДМ встречается значительно реже, чем с ЮИА и ЮССД. Известны немногочисленные описания этой комбинации у пациентов различного возраста [12-16]. Лишь в одной из указанных статей описываются 2 случая дебюта СД1 вскоре после диагностики ЮДМ у детей на фоне уже проводимой терапии [14]. Диагноз СД1 в одном из описываемых клинических примеров, как и в нашем случае, был доказан на основании положительного титра антител, специфичных для СД1. Во втором клиническом примере у тех же авторов не удалось получить доказательства аутоиммунного генеза диабета, и диагноз СД1 был установлен на основании клинических данных [14].

Воспалительные заболевания кишечника (ВЗК), К которым относят ЯК и болезнь Крона (БК), - это группа системных хронических рецидивирующих воспалительно-деструктивных заболеваний, приводящих к необратимому нарушению структуры и функции желудочно-кишечного тракта. ЯК возникает первоначально в слизистой оболочке прямой кишки и может восходяще распространяться на все отделы толстой кишки, иногда вовлекается терминальный отдел подвздошной кишки. Заболеваемость ВЗК у детей значительно отличается по географическим регионам, для ЯК составляет 1-4 случая [17-19], для БК - 2,2-11,4 на 100000 детей в год $[17,20]$. До 15-20\% случаев ЯК и БК начинается в детском возрасте. На сегодняшний день наблюдается рост распространенности и заболеваемости ВЗК, отмечается «омоложение» болезни, более динамичный прирост заболеваемости БК, нежели ЯК. Распространенность СД1 при В3К достаточно высока. Согласно результатам исследования, в котором приняли участие 379 медицинских центров Германии и Австрии, ЯК был выявлен у 63 из 65147 детей и подростков с СД1 [21]. Таким образом, ЯК был диагностирован у 1 из 1000 пациентов с СД1. Нам не удалось найти аналогичные отечественные данные, однако с учетом распространенности СД1 среди детского населения в Российской Федерации [2] можно предположить, что в нашей стране может быть около 20 подобных пациентов детско-подросткового возраста.

Для пациентов с ЯК типичны меньший ИМТ и высокий риск тяжелых гипогликемий по сравнению с остальными пациентами с СД1. У нашей пациентки на момент поступления в УДКБ SDS ИМТ соответствовал нижней границе нормы (-1,84), а за полгода до этого, в период обострения заболевания, когда пациентка получала ГК, согласно данным медицинской документации, соответствовал дефициту массы тела $(-2,54)$. Интересно отметить, что высокая потребность в инсулине и относительно неудовлетворительный уровень компенсации были типичны для нашей пациентки лишь в периоды приема больших доз ГК, тогда как на фоне снижения доз отмечалась склонность к гипогликемиям. Согласно литературным данным, для этой группы пациентов типичны склонность к гипогликемиям и высокий риск тяжелых гипогликемий. Считается, что это обусловлено как дефицитом массы тела, так и нарушением всасывания [21].

Реактивный apmpum - асептическое воспалительное заболевание суставов, развивающееся в ответ на внесуставную инфекцию, преимущественно кишечную и урогенитальную. Распространенность РА в России среди детей до 14 лет составляет 90,76 на 100000 детского населения, а среди подростков 15-17 лет - 139,64 на 100000 [3]. У описываемого нами пациента РА протекает без отчетливых внесуставных проявлений, с типичным асимметричным поражением суставов нижней конечности. С целью купирования суставного синдрома при РА обычно применяют НПВП, что было неэффективным у описываемого нами пациента. Внутрисуставное введение ГК является одним из наиболее широко используемых методов лечения РА.

Применение ГК у пациентов с СД1 ухудшает гликемический контроль [4]. В связи с этим у многих врачей бытует мнение, что назначение ГК при СД1 противопоказано. Однако обострение воспаления при отсутствии адекватной терапии приводит к значительно более длительной декомпенсации СД1, что наглядно продемонстрировано данными мониторинга гликемии пациента с РА.

В приведенных клинических случаях внутрисуставное введение ГК не оказывало значительного влияния на гликемию (пациенты с ЮИА и РА), пульс-терапия ГК приводила к временной декомпенсации углеводного обмена (пациенты с ЮИА, ЮССД и ЯК), а наиболее значимым гипергликемическим эффектом сопровождалось применение пероральной терапии ГК в высоких дозах (пациенты с ЮССД, ЮДМ и ЯК).

При проведении пульс-терапии ГК гипергликемия и повышенная потребность в инсулине в описываемых нами случаях нарастала спустя 3-6 ч после приема ГК (через 6 ч у пациенток с ЮИА и ЮССД, через 3 ч у пациентки с ЯК), сохранялась от нескольких часов до 3 сут после каждого введения. Полученные нами результаты согласуются с литературными данными. Например, на основании клэмп-исследований у взрослых известно, что инсулинорезистентность развивается спустя 4 ч после начала введения ГК [22]. В то же время на фоне 3 дней приема ГК взрослыми пациентами продемонстрировано увеличение потребности в болюсном инсулине в среднем через 6 ч после первого введения ГК, а возвращение к исходной потребности - к концу 2-х суток после последнего введения ГК [23].

По данным литературы, у взрослых потребность в инсулине может увеличиваться в среднем на 69\% (от 30 до 100\%) [22]. У наблюдаемых нами пациентов суточная доза инсулина была индивидуальна и достигала 1,8-2,0 Ед/кг (увеличение приблизительно на 100\%) у пациентов с длительностью СД1 в течение нескольких лет (пациентки с ЮИА, ЮССД). У пациентки с ЯК проведение повторной пульс-терапии на фоне обострения прервало период полной клинико-лабораторной ремиссии, длившийся 3 мес, и потребовало возобновления интенсифицированной схемы инсулинотерапии.

В качестве методов, позволяющих преодолеть колебания гликемии на фоне терапии ГК, согласно данным литературы, предлагается использовать аналоги инсули- 
на ультракороткого действия, ингибиторы глюкозидазы и бигуаниды для уменьшения инсулинорезистентности [4]. У наших пациентов, длительно получавших пероральные ГК (пациенты с ЮССД, ЮДМ и ЯК), возможность назначения ингибиторов глюкозидазы и бигуанидов не рассматривалась ввиду возможных дополнительных побочных эффектов со стороны желудочно-кишечного тракта. Во всех случаях мы проводили коррекцию инсулинотерапии с увеличением доз препаратов в зависимости от потребности пациентов.

При подборе инсулинотерапии на фоне длительного лечения таблетированными препаратами ГК необходимо учитывать время их приема пациентом. Традиционно при ревматических заболеваниях вся доза ГК назначается на ранние утренние часы, а при большой дозе возможно ее деление на 2-3 приема (6, 9, 12 ч утра). В соответствии со временем приема ГК, наихудший контроль гликемии отмечался у наших пациентов в дневное время. Для преодоления инсулинорезистентности использовались перенос инъекции гларгина на утренние часы (пациент с ЮДМ), увеличение на 10\% дозы пролонгированного инсулина и дополнительные инъекции ультракороткого инсулина (пациентка с ЮССД). Кроме этого, пациенту с ЮДМ вместо аналога инсулина ультракороткого действия был временно назначен человеческий инсулин короткого действия (на фоне приема 45 мг преднизолона и дальнейшего постепенного снижения дозы до 10 мг).

У наших пациентов была отмечена еще одна особенность инсулинотерапии на фоне введения ГК - увеличение доз болюсного инсулина по сравнению с дозами базального инсулина. Первоначально мы предполагали, что подобная тенденция (увеличение потребности в инсулине приблизительно в 2 раза исключительно за счет болюсов) у пациенток с ЮИА и ЮССД в большей степени была связана с декомпенсацией СД1 и недостаточными усилиями по коррекции инсулинотерапии. Однако аналогичная тенденция прослеживалась и у пациентов с высоким уровнем комплаентности (пациенты с ЮДМ, ЯК и РА). Оказалось, что, согласно результатам исследований, у взрослых подобное перераспределение доз повышает вероятность достижения нормогликемии в период приема ГК [24].

После перевода на поддерживающие дозы ГК или при прекращении терапии ГК пациенты возвращались к стандартной (пациенты с ЮИА, ЮССД и РА) или относительно низкой (пациенты с ЮДМ и ЯК) потребности в инсулине.
Показатели $\mathrm{HbA}_{1 c}$ значительно различались между пациентами на разных этапах лечения, были максимальными на фоне продолжительной терапии высокими дозами таблетированных ГК (пациенты с ЮДМ и ЯК), но в большей степени зависели от уровня комплаентности пациента.

\section{ЗАКЛЮЧЕНИЕ}

На основании сопоставления течения СД1 у пациентов с РА, ЮИА, ЮССД, ЮДМ и ЯК, получавших различные формы и дозы ГК в различные периоды заболеваний, можно сделать выводы об удовлетворительной переносимости проводимой терапии ГК.

Несмотря на очевидное ухудшение контроля гликемии в кратковременный период приема высоких доз ГК, компенсации гликемии удается добиться при своевременной коррекции доз инсулинотерапии, подборе индивидуальных схем, учитывающих время приема ГК. Существенный вклад в компенсацию углеводного обмена вносит степень приверженности пациента и его семьи к лечению СД1.

Для комплексного подхода к лечению таких пациентов необходимо тесное взаимодействие врача, занимающегося лечением заболевания, требующего назначения терапии ГК, с детским эндокринологом и семьей пациента.

\section{ДОПОЛНИТЕЛЬНАЯ ИНФОРМАЦИЯ}

Согласие пациента. Законные представители каждого из пациентов добровольно подписали информированные согласия на публикацию персональной медицинской информации в обезличенной форме в журнале «Сахарный диабет».

Конфликт интересов. Авторы декларируют отсутствие явных и потенциальных конфликтов интересов, связанных с публикацией настоящей статьи.

Участие авторов. Витебская А.В. - концепция и дизайн статьи, консультирование пациентов, анализ литературы, написание текста, редактирование; Попович А.В., Афонина Е.Ю., Костина Ю.О., Алексанян К.В., Грамматопуло М.И. - курация пациентов, сбор данных; Яблокова Е.А. - консультирование пациентов, анализ литературы, написание текста; Шпитонкова О.В. - консультирование пациентов, редактирование. Все авторы внесли значимый вклад в проведение исследования и подготовку статьи, прочли и одобрили финальную версию статьи перед публикацией.

\section{СПИСОК ЛИТЕРАТУРЫ | REFERENCES}

1. Федеральные клинические рекомендации (протоколы) по ведению детей с эндокринными заболеваниями. / Под ред. Дедова И.И., Петерковой В.А. - М.: Практика; 2014. [Dedov II, Peterkova VA, editors. Federal'nye klinicheskie rekomendatsii (protokoly) po vedeniyu detey sendokrinnymi zabolevaniyami. Moscow: Praktika; 2014. (In Russ.)]

2. Дедов И.И., Шестакова М.В., и др. Сахарный диабет в Российской Федерации: распространенность, заболеваемость, смертность, параметры углеводного обмена и структура сахароснижающей терапии по данным Федерального регистра сахарного диабета, статус 2017 г. // Сахарный диабет. — 2018. - T. 21. — №3. C. 144-159. [Dedov II, Shestakova MV, Vikulova OK, et al. Diabetes mellitus in Russian Federation: prevalence, morbidity, mortality, parameters of glycaemic control and structure of glucose lowering therapy according to the Federal Diabetes Register, status 2017.

Diabetes mellitus. 2018;21(3):144-159. (In Russ.)]

https://doi.org/10.14341/DM9686
3. Руководство по детской ревматологии. / Под ред. Геппе Н.А., Подчерняевой Н.С., Лыскиной Г.А. — М.: ГЭОТАР-Медиа; 2011. [Geppe NA, Podchernyaeva NS, Lyskina GA, editors. Rukovodstvo po detskoy revmatologii. Moscow: GEOTAR-Media; 2011. (In Russ.)]

4. Jannot-Lamotte MF, Raccah D. Management of diabetes during corticosteroid therapy. Presse Med. 2000;29(5):263-266.

5. Hermann G, Thon A, Monkemoller K, et al. Comorbidity of type 1 diabetes and juvenile idiopathic arthritis. J Pediatr. 2015;166(4):930935 e931-933. https://doi.org/10.1016/j.jpeds.2014.12.026

6. Emamifar A, Levin K, Jensen Hansen IM. Patients with newly diagnosed rheumatoid arthritis are at increased risk of diabetes mellitus: an observational cohort study. Acta Reumatol Port. 2017;42(4):310-317.

7. Pohjankoski H, Kautiainen H, Korppi M, Savolainen A. Simultaneous juvenile idiopathic arthritis and diabetes mellitus type 1 -a Finnish nationwide study. J Rheumatol. 2012;39(2):377-381. https://doi.org/10.3899/jrheum.110654 
8. Tseng CC, Chang SJ, Tsai WC, et al. Reduced incidence of Type 1 diabetes and Type 2 diabetes in systemic sclerosis: A nationwide cohort study. Joint Bone Spine. 2016;83(3):307-313. https://doi.org/10.1016/j.jbspin.2015.06.017

9. Pavlovic MD, Milenkovic T, Dinic M, et al. The prevalence of cutaneous manifestations in young patients with type 1 diabetes. Diabetes Care. 2007;30(8):1964-1967. https://doi.org/10.2337/dc07-0267

10. Yosipovitch G, Hodak E, Vardi P, et al. The prevalence of cutaneous manifestations in IDDM patients and their association with diabetes risk factors and microvascular complications. Diabetes Care. 1998;21(4):506-509. https://doi.org/10.2337/diacare.21.4.506

11. Алексеева Е.И., Маслиева Р.И., Лыскина Г.А., Бзарова Т.М. Федеральные клинические рекомендации по оказанию медииинской помощи детям с ювенильным дерматомиозитом. / Под ред. Баранова А.А. — 2015. [Alekseeva El, Maslieva RI, Lyskina GA, Bzarova TM. Baranov AA, editor. Federal'nye klinicheskie rekomendatsii po okazaniyu meditsinskoy pomoshchi detyam syuvenil'nym dermatomiozitom. 2015. (In Russ.)]

12. Kosik VN. A combination of diabetes mellitus and dermatomyositis. Vrach Delo. 1969;9:143.

13. Sattar MA, Al-Sughyer AA, Siboo R. Coexistence of Rheumatoid Arthritis, Ankylosing Spondylitis and Dermatomyositis in a Patient with Diabetes Mellitus and the Associated Linked Hla Antigens. Rheumatology. 1988;27(2):146-149. https://doi.org/10.1093/rheumatology/27.2.146

14. Singh R, Cuchacovich R, Gomez R, et al. Simultaneous occurrence of diabetes mellitus and juvenile dermatomyositis: report of two cases. Clin Pediatr (Phila). 2003;42(5):459-462. https://doi.org/10.1177/000992280304200514

15. Charalabopoulos K, Charalabopoulos A, Papaioannides D. Diabetes mellitus type I associated with dermatomyositis: an extraordinary rare case with a brief literature review. BMJ Case Rep. 2009;2009. https://doi.org/10.1136/bcr.10.2008.1158

16. McClanahan CM, Smith HL, Garner SA. Co-occurrence of dermatomyositis and Hashimoto's thyroiditis in a type I diabetic patient. QJM. 2015;108(4):331-333.

https://doi.org/10.1093/qjmed/hcs152
17. Benchimol El, Fortinsky KJ, Gozdyra P, et al. Epidemiology of pediatric inflammatory bowel disease: a systematic review of international trends. Inflamm Bowel Dis. 201 1;17(1):423-439. https://doi.org/10.1002/ibd.21349

18. Heyman MB, Kirschner BS, Gold BD, et al. Children with earlyonset inflammatory bowel disease (IBD): analysis of a pediatric IBD consortium registry. J Pediatr. 2005;146(1):35-40. https://doi.org/10.1016/j.jpeds.2004.08.043

19. Потапов АС, Алиева ЭИ, Габрузская ТВ, и др. Клиническая картина, диагностика и лечение язвенного колита у детей: Российский педиатрический консенсус (репринт) // Вопросы современной neдиampuu. - 2013. - T. 12. - №3. - C. 1-9. [Potapov AS, Alieva El, Gabruzskaya TV, et al. Clinical manifestation, diagnostics and treatment of ulcerative colitis in children: russian pediatric consensus. Current Pediatrics. 2013;12(3):18-30. (In Russ.)] https://doi.org/10.15690/vsp.v12i3.677

20. Ruemmele FM, Veres $\mathrm{G}$, Kolho KL, et al. Consensus guidelines of ECCO/ESPGHAN on the medical management of pediatric Crohn's disease. J Crohns Colitis. 2014;8(10):1179-1207. https://doi.org/10.1016/j.crohns.2014.04.005

21. Jasser-Nitsche H, Bechtold -Dalla Pozza S, Binder E, et al. Inflammatory bowel disease in children and adolescents with type 1 diabetes: a multicenter analysis from the German-Austrian DPV database. Pediatr diabetes. 2016,17(S24):2

22. Zarkovic M, Beleslin B, Ciric J, et al. Glucocorticoid effect on insulin sensitivity: a time frame. J Endocrinol Invest. 2008;31 (3):238-242. https://doi.org/10.1007/BF03345596

23. Bevier WC, Zisser HC, Jovanovic L, et al. Use of continuous glucose monitoring to estimate insulin requirements in patients with type 1 diabetes mellitus during a short course of prednisone. J Diabetes Sci Technol. 2008;2(4):578-583. https://doi.org/10.1177/193229680800200408

24. Spanakis EK, Shah N, Malhotra K, et al. Insulin requirements in non-critically ill hospitalized patients with diabetes and steroid-induced hyperglycemia. Hosp Pract. 2014;42(2):23-30. https://doi.org/10.3810/hp.2014.04.1100

\section{ИНФОРМАЦИЯ ОБ АВТОРАХ [AUTHORS INFO]}

*Витебская Алиса Витальевна, к.м.н. [Alisa V. Vitebskaya, MD, PhD]; адрес: Россия, 119881, Москва, ул. Б.Пироговская, д. 19 [address: 19 В.Pirogovskaya street, 119881 Moscow, Russian Federation]; ORCID: http://orcid.org/0000-0001-5689-0194; eLibrary SPIN: 9857-9551; e-mail: dr.vitebskaya@gmail.com

Попович Анастасия Владимировна [Anastaiya V. Popovich, MD]; ORCID: http://orcid.org/0000-0002-9660-8795; eLibrary SPIN: 3241-4064; e-mail: krutova_nastasya@mail.ru

Афонина Елена Юрьевна, к.M.н. [Elena Y. Afonina, MD, PhD]; ORCID: http://orcid.org/0000-0001-9643-5567; eLibrary SPIN: 2904-7080; e-mail: lenaf23@mail.ru

Костина Юлия Олеговна, К.M.H. [Yuliya O. Kostina, MD, PhD]; ORCID: http://orcid.org/0000-0002-6389-5177; eLibrary SPIN: 1240-9417; e-mail: julialonkos@mail.ru

Алексанян Карина Владимировна [Karina V. Aleksanyan, MD]; ORCID: http://orcid.org/0000-0002-5339-8169; eLibrary SPIN: 1682-6967; e-mail: alex-karina@mail.ru

Грамматопуло Мария Ивановна [Mariya I. Grammatopulo, MD]; ORCID: http://orcid.org/0000-0002-5203-3053; eLibrary SPIN: 9908-7274; e-mail: marula1957@yandex.ru

Яблокова Екатерина Александровна, к.м.н. [Ekaterina A. Yablokova, MD, PhD]; ORCID: http://orcid.org/0000-0003-3364-610X; eLibrary SPIN: 9347-8757; e-mail: catcom@list.ru

Шпитонкова Ольга Викторовна, к.M.н. [Olga V. Shpitonkova, MD, PhD];

ORCID: http://orcid.org/0000-0001-8132-0169; eLibrary SPIN: 4180-5996; e-mail: shpitonkov@rambler.ru

\section{ЦИТИРОВАТЬ:}

Витебская А.В., Попович А.В., Афонина Е.Ю., Костина Ю.О., Алексанян К.В., Грамматопуло М.И., Яблокова Е.А., Шпитонкова О.В. Особенности инсулинотерапии при сахарном диабете 1 типа у детей и подростков, получающих глюкокортикоиды // Сахарный диабет. - 2019. - Т. 22. - №3. — С. 263-273. doi: 10.14341/DM10042

\section{TO CITE THIS ARTICLE:}

Vitebskaya AV, Popovich AV, Afonina EY, Kostina YO, Aleksanyan KV, Grammatopulo MI, Yablokova EA, Shpitonkova OV. Characteristics of insulin therapy of diabetes mellitus type 1 in children and adolescents receiving glucocorticoids. Diabetes Mellitus. 2019;22(3):263-273. doi: 10.14341/DM10042 